\title{
Assessing the Billy Ireland Cartoon Library and Museum Collection Needs: A Case Study on Collection Surveys
}

\author{
By Wendy Pflug
}

ABSTRACT: This case study examines the planning, methodology, and impact of a comprehensive collections survey at the Billy Ireland Cartoon Library and Museum at The Ohio State University Libraries. Collections consisting of original cartoon art, archives, objects, and published materials were systematically surveyed and assessed to develop a prioritized processing plan targeted at improving accessibility. The collections survey encompassed all holdings — processed and unprocessed — and all formats of materials. The survey centralized long-scattered collection information and provided the unexpected benefit of documenting institutional memory during a time of transition and expansion.

\section{Introduction}

The Billy Ireland Cartoon Library and Museum (BICLM), a special collection division at The Ohio State University Libraries (OSUL), holds unique collections of original art, artifacts, and archival and manuscript materials related to cartoon and comic history. Since its founding in 1977, the BICLM has experienced exponential growth documenting cartoon history and comic art through the acquisition of the papers, original art, and related materials of many influential American cartoonists such as Milton Caniff, Will Eisner, and Bill Watterson. In 2012, the BICLM began final preparations for a major expansion and move to a renovated facility on central campus with increased collection storage areas, three galleries for the exhibition of original cartoon art, and a focus on establishing a new museum component. During this time, several major staffing changes occurred, including the founding curator's retirement, the former associate curator's promotion to head curator, and two new hires: an associate curator for collections and a visiting curator focused on outreach. Both new staff members came from other institutions and were unfamiliar with the majority of collections. The BICLM faced the potential loss of years of institutional knowledge and needed to gain physical and intellectual control over the collections to meet the immediate goals associated with moving into a new facility and the long-term goal of increasing access to materials.

Among its challenges, the BICLM faced a sizable backlog after absorbing large collections from two former cartoon institutions: the San Francisco Academy of Comic Art (SFACA), whose collection included 2.5 million newspaper comic tear sheets, ${ }^{1}$ and the original art collection from the defunct International Museum of Cartoon Art (IMCA), founded by Beetle Bailey comic strip creator, Mort Walker. Other significant holdings include the proof libraries of newspaper comic strip syndicates King Features 
and United Media. Current holdings at the time of the BICLM move included more than 300,000 original cartoons, 45,000 books, 67,000 serials and comic books, and 3,000 linear feet of manuscript materials. ${ }^{2}$ The unique mixture of original art, published items, archival materials, and objects, often found within a single collection, sometimes makes collection-level description challenging. To accommodate the multiple formats, three different, separate description systems are used: original art is cataloged on the item level using PastPerfect, a museum collection management software; ${ }^{3}$ books, serials, and comic books are described with a MARC record in the library catalog; and archival and manuscript materials are described with a finding aid, available online in EAD or on-site as a paper guide. Additionally, the BICLM backlog included a number of unprocessed and underprocessed collections and materials described within legacy inventories available only on-site. While numerous collections of original art are fully cataloged, access to manuscript, record, and ephemera collections depended on the expertise and institutional knowledge of the founding curator, now emeritus, and long-time staff in part because the three description systems are not integrated. These issues, in addition to many collections lacking online descriptions, kept the BICLM holdings hidden and not discoverable independently by researchers. Even the BICLM staff could not compile a list of all the collections within their holdings. The goal of improving access could be met by processing collections, creating online finding aids, and introducing collectionlevel catalog records.

However, before work could begin on these projects, BICLM needed a collections assessment to determine where and how to start. Several larger institutions have undertaken collections assessments by surveying, including the Philadelphia Area Consortium of Special Collection Libraries (PACSCL), which made a multirepository survey of unprocessed collections. Could BICLM accomplish a survey without the additional resources provided by grant funding? At a basic level, the BICLM was unsure of how to structure effective survey methodology or survey duration. What resources were available for planning a collections assessment survey? Using methodology adapted from larger projects, the BICLM set out to survey everything in its holdings and develop a prioritized processing plan focused on increasing accessibility. During the survey process, the BICLM discovered that the survey provided the unexpected benefit of documenting the institutional memory during a time of transitions and expansion.

\section{Literature Review}

A review of literature located the 2011 OCLC research report Taking Stock and Making Hay: Archival Collection Assessment by Martha O'Hara Conway and Merrilee Proffitt. The report defines archival collections assessment as a "systematic, purposeful gathering of information" 4 and encompasses surveys of all purposes including appraisal, prioritizing of processing, conservation, and other collections management activities. Among the benefits of survey assessment is better understanding of collections by amassing comprehensive information on the level of description available, evaluating preservation concerns, and allocating resources needed to meet institutional needs. For those wishing to improve access, it seems strategic to begin surveying holdings to 
measure the state of collections. Conway and Proffitt observed that although many repositories conduct survey assessments, a single approach does not exist and would be impractical. ${ }^{5}$ Instead, Taking Stock and Making Hay breaks down the necessary components of an efficient archival collections assessment, such as identifying the survey's scope, which will shape other elements of the survey: collecting quantitative and qualitative information, methodology, and staffing. ${ }^{6}$ Other elements like the availability of resources including human, financial, time, and physical space also need to be considered when establishing the scope of an archival collections assessment survey. Conway and Proffitt stated that these resources may be constrained in many institutions, and the scope of the project needs to be created with these limitations in mind. ${ }^{7}$ The authors also identified successful projects undertaken by various institutions intending the report and examples to provide methodologies and tools that could be adapted to fit the needs of a variety of repositories.

Several practical sources exist on the subject of planning and administering collections surveys. The SAA Basic Manual Archives and Manuscripts: Surveys by John A. Fleckner offers pragmatic suggestions on planning, conducting, and completing a records survey, such as immediately defining the scope of the survey, which will direct the project, ${ }^{8}$ similar to Conway and Proffitt's suggestion of necessary components. While Fleckner's manual emphasizes conducting historical records surveys, much of the discussion, such as that around "information elements commonly gathered by records surveyors," applied to collection assessment surveys. Gregory S. Hunter's Developing and Managing Practical Archives encourages the use of surveys as an effective collections management tool, but advises, "Any survey, even a small one, is a complex task. It will require a great deal of time and effort, resulting in the diversion of staff time from other activities." ${ }^{10}$ Surveys require additional resources; the most basic requirement is staff time to conduct the assessment, which may cause reluctance to commit to such a project. In a period of reduced resources and many competing interests, surveying collections is not a regular practice in most repositories. ${ }^{11}$ Especially if the practice has not been a regular occurrence, surveying may seem like an insurmountable task. Indeed, the professional literature focuses primarily on the reasons for collections surveys and lacks specific data on surveys' effectiveness and completion rates despite limitations.

While Taking Stock and Making Hay reports that a single approach in survey methodology does not exist, procedures from a variety of projects can be adapted to fit a myriad of purposes. The article's Appendix A summarizes 14 collections survey projects successfully undertaken ${ }^{12}$ by various institutions and provides links to websites containing the project documentation and survey models, such as the Philadelphia Area Consortium of Special Collections Libraries Consortial Survey Initiative. The initiative, a 30-month project (2006-2008) funded by an Andrew W. Mellon Foundation grant, planned to "assess unprocessed, underprocessed, and underdescribed archival collections in a range of physical formats at the twenty-two member repositories in the Philadelphia area." ${ }^{13}$ Assisting with planning and prioritization of collections management projects would enhance access and produce a tangible result by creating collection-level catalog records available to the public. Based on a survey developed 
at the Historical Society of Pennsylvania, Columbia University and the University of Virginia later successfully adapted PACSCL's assessment model for their own uses. However, the PACSCL survey was the first instance "that the model is being applied cross-institutionally and to a range of types of academic and cultural institutions." ${ }^{14}$ According to project documentation, "the survey instrument provides for the qualitative and quantitative assessment of a number of physical and intellectual characteristics of collections, including physical condition, quality of housing, physical access, intellectual access, quality of documentation, and interest." ${ }^{15}$ PACSCL used teams of no less than two people to inspect the collection materials visually while consulting any available descriptive tools. The surveyors assigned ratings to the physical and intellectual characteristics of each collection and included an explanation for their numerical rankings (1 to 5), ratings for interest and quality, which indicated the following: ${ }^{16}$

Table 1: PACSCL Research Value Rating Scale

\begin{tabular}{|l|l|l|}
\hline Interest Level Value & Value Scale & Quality of Documentation Value \\
\hline Very High & 5 & Very Rich \\
\hline High & 4 & Rich \\
\hline Moderate & 3 & Moderately Rich \\
\hline Slight & 2 & Incidentally Valuable \\
\hline Negligible & 1 & Slight \\
\hline
\end{tabular}

Survey teams gathered information in a shared FileMaker Pro database, designed specifically for the project. This database compiled information on each surveyed collection including bibliographic information, assessment ratings, name and subject headings, and administrative information. To provide access to the collections, the bibliographic fields in the database mapped to MARC, sharing individual member repositories' collections metadata with union catalogs and local OPACS. The results of the PACSCL Consortial Survey Initiative also enabled a successful grant application from the Council on Library and Information Resources (CLIR) to fund the Hidden Collections processing project, which specifically focused on collections identified as having a high research value in the survey.

The experience of the PACSCL Consortial Survey Initiative influenced and provided a model for other institutions to conduct unprocessed collections surveys. In 2011, the larger Ohio University Library Special Collections Unit began an unprocessed collections assessment survey modeled after PACSCL. The Special Collections Unit Survey focused only on unprocessed materials at the main Thompson Library. In contrast, the BICLM Collections Survey, begun in 2012, acquainted new staff with the materials and included all of the BICLM's holdings, not just the unprocessed materials in the larger OSUL Special Collections Unit Survey. ${ }^{17}$ Initially, the BICLM staff worked with the unprocessed collections survey project manager and contributed information on the BICLM's unprocessed materials to a proposed Special Collections Unit Unprocessed Collections Database. ${ }^{18}$ 


\section{Methodology of the BICLM Collections Survey}

Early in the project planning, the BICLM decided to survey all the collection holdings, both processed and unprocessed, primarily because of the new staff's unfamiliarity with collection strengths and levels of accessibility. The BICLM lacked consistent information for all its collections, which, coupled with the backlog's issues and the collections' lack of discovery, hindered effective collection management decisions. Therefore, the goals of the BICLM Collections Survey were to assess what collections the BICLM's holdings contained, where collections were located, and what needed to be done for users to access materials from the BICLM's finding tools without assistance from a staff member.

The BICLM's curator and associate curator discussed what information should be gathered in the survey. Based on BICLM's needs, the survey would capture the following information:

Table 2: Gathered Collection Survey Information Fields

\begin{tabular}{|c|c|}
\hline ISurvey Information Fields & BICLM Collection Information \\
\hline Collection Title* & Eldon Dedini Collection \\
\hline $\begin{array}{l}\text { Collection Code (accession number or other } \\
\text { unique identifier)** }\end{array}$ & CGA.ED.2006 \\
\hline Brief Subject Description of Collection & $\begin{array}{l}\text { Magazine cartoonist who drew for publications } \\
\text { such as the New Yorker, Esquire, Playboy, and } \\
\text { many others from 1940s to } 2005 \text {. }\end{array}$ \\
\hline Extent* & $\begin{array}{l}\text { Over } 1,000 \text { items of original art } \\
138 \text { manuscript boxes }\end{array}$ \\
\hline Location (physical location; stacks or offsite) & Stacks: Ranges 36-41 and Art Cases AG 1-10 \\
\hline $\begin{array}{l}\text { Collection Contents:** } \\
\text { Original Art } \\
\text { Manuscripts/ Archives } \\
\text { Memorabilia/ Objects } \\
\text { Published Materials } \\
\text { Scrapbooks } \\
\text { Audio/Visual }\end{array}$ & $\begin{array}{l}\text { Original Art } \\
\text { Manuscripts/ Archives } \\
\text { Memorabilia/ Objects } \\
\text { Published Materials } \\
\text { Scrapbooks }\end{array}$ \\
\hline \multicolumn{2}{|c|}{ Description Level of the Collection (what discovery tools are available? Select all that apply):** } \\
\hline Past Perfect Records & Yes \\
\hline $\begin{array}{l}\text { MARC catalog record (include hyperlink to } \\
\text { catalog record, if applicable) }\end{array}$ & $\begin{array}{l}\text { Yes- separated published materials; } \\
\text { Need Collection Level to represent art and } \\
\text { archives }\end{array}$ \\
\hline Finding Aid (EAD: available online) & Need \\
\hline Inventory (paper or available onsite only) & Yes- Excel Files \\
\hline \multicolumn{2}{|l|}{ None } \\
\hline Is more material expected (Yes or no)** & No \\
\hline Physical Condition Rating (1 to 5$)^{*}$ & 4 \\
\hline Processing Status* & Mostly Underprocessed \\
\hline Interest Rating (1 to 5$)^{*}$ & 4 \\
\hline Quality Rating (1 to 5)* & 5 \\
\hline Is the collection a candidate for digitization?*** & Yes \\
\hline $\begin{array}{l}\text { Notes (remarks from the BICLM founding } \\
\text { Curator) }\end{array}$ & $\begin{array}{l}\text { Spreadsheet can be converted into EAD file; } \\
\text { exhibit of artwork planned for new space in } 2016 .\end{array}$ \\
\hline \multicolumn{2}{|c|}{$\begin{array}{l}\text { * These fields were used in the OSUL Special Collections Unprocessed Survey and the } \\
\text { PACSCL Consortial Survey Initiative }\end{array}$} \\
\hline
\end{tabular}


While a separate project that used methodology different from the Special Collections Unit unprocessed survey, the BICLM Collections Survey adopted several of the same fields including processing status; physical condition rating; interest rating; and quality rating. This ensured BICLM's data could be reused to populate the planned Special Collections Unit Unprocessed Collections Database. The Special Collections Unit modeled its survey after PACSCL Consortial Survey Initiative and used PACSCL's ranking terminology to define processing status as "completely unprocessed," "mostly unprocessed," "mostly underprocessed," and "has unprocessed material." Similarly, PACSCL's numerical rankings for the interest rating and quality rating were used in the Special Collections Unit unprocessed survey.

Fields such as collection code, collection contents, description level of the collection, and is more material expected, were created to meet the unique needs of the BICLM Collections Survey. These fields were necessary for several reasons. First, after reviewing accession files, it appeared multiple collections had the same three-letter code (indicating donor or collection subject when accessioned), which was problematic as the collection code later became the collection's call number or unique identifier. Second, the BICLM curator needed collections containing audiovisual media indicated for quick reference when planning future reformatting projects. Finally, information on the level of description available would indicate discoverability by researchers. Other fields, such as is more material expected, would help determine processing priority. If more materials are to be added to a collection, the curator may prefer to wait to process the collection until the additional items are received.

\section{Conducting the Survey}

The associate curator conducted the survey. Since the BICLM Collections Survey encompassed all holdings, she began by reviewing the ways the library traditionally provided access to the many different formats in collections to determine processing status. Unprocessed and processed collections information was scattered across a variety of sources, from correspondence in donor files, handwritten inventories, and finding aids in digital legacy formats, to outdated range guides and even an old card catalog. However, documentation quality was comprehensive. The founding curator kept copies of all her correspondence and later printed out every e-mail for the donor files. Additionally, electronic files containing legacy information were accessible, so it was possible to trace collections' individual accessions. The Ohio State University Libraries' online catalog provided information on processed collections, including some collection-level records containing hyperlinks to the finding aid or to the BICLM PastPerfect Original Art Database. The catalog enabled the associate curator to check the degree to which a collection was processed. Collections with records were assessed to see if the hyperlinks were still working, if links needed to be added, and for accuracy. 
After the initial collections data gathering was complete, work began on physical inspection by examining boxes shelf by shelf, range by range of the stacks, and at an off-site depository to confirm, update, revise, or add information from the various sources. The associate curator compiled the information into an Excel spreadsheet. Next, the entire staff met and reviewed the gathered information. In 2012, the BICLM staff included four permanent employees and the retired founding curator (in a consulting role). The staff met on eight separate occasions for about two hours each, reviewing the findings, drawing on the founding curator's institutional memory, and collectively rating the qualitative fields, interest, and quality by entering the information directly into the spreadsheet. This was a very involved, time-consuming step due to the discussions among the staff; however, they found it extremely useful to record the founding curator's intuitional memory into the accessible format of a spreadsheet. It allowed staff to understand the larger issues of collections management.

\section{Outcomes and Impact of the BICLM Collections Survey}

The BICLM Collections Survey took approximately 12 months to complete, six months longer than originally anticipated. A temporary staff leave of absence accounted for part of this delay. However, the decision to conduct a survey of all holdings rather than just the unprocessed collections was the primary reason for the larger time investment. Surveying the complete holdings involved an additional component: analyzing collections to assess what was completed and what needed to be done for a collection to be considered processed. Initially, the associate curator attempted to record information on the preservation status and possible items and collections to digitize within the survey form. However, upon further discussion, staff decided that the extra time spent on assessing preservation and digitization possibilities took focus away from the original goal of understanding the state of BICLM's collection holdings. A survey assessing preservation or digitization candidates will be a separate project.

In retrospect, the PACSCL Interest Ranking Value Scale, where 5 equals very high and 1 equals negligible researcher interest, proved frustrating to the BICLM. Specifically included in BICLM's survey to align with the Special Collections Unit unprocessed collection survey, the BICLM staff felt the ranking an arbitrary indicator of interest and that all holdings merited a very high interest rating depending on potential researchers' topics. To assist with the ranking of interest value, the staff looked at usage statistics from the reading room and requests for digital images to determine past use of a collection. The founding curator also shared her recollections of past uses of the collections to help assign research interest.

The BICLM found it useful to define the following terms, indicating the degree to which a collection was considered processed. 
Table 3: Degree of Processing Status Definitions

\begin{tabular}{|l|l|}
\hline Processing Status Terms & Definition \\
\hline Processed & $\begin{array}{l}\text { Collection has a digital access point through OSUL catalog, art database } \\
\text { record, or EAD: either all three access points or a combination thereof. } \\
\text { The researcher can presumably find without any assistance from staff. }\end{array}$ \\
\hline Mostly Processed & $\begin{array}{l}\text { Majority of collection has digital access points through catalog, art data- } \\
\text { base, or EAD. If collection does have not an EAD (and has manuscript } \\
\text { material), there is a written finding aid or fairly complete inventory to } \\
\text { create an EAD. May have broken links in catalog record to art database } \\
\text { or Ohio Link EAD Repository. Collection can presumably be found by } \\
\text { researchers without major staff assistance. }\end{array}$ \\
\hline Has Unprocessed Materials & $\begin{array}{l}\text { While there is a digital access point, some material is unprocessed or } \\
\text { underdescribed (e.g., such as a very basic catalog record or has catalog } \\
\text { record with broken links to art database). Most of the collection can be } \\
\text { found without staff assistance, but a portion is hidden to researchers. }\end{array}$ \\
\hline Mostly Underprocessed & $\begin{array}{l}\text { There might be a digital access point, but it needs updating or further } \\
\text { description to improve accessibility. The main form of access is a written } \\
\text { outline of collection contents available only in-house. A staff member } \\
\text { could provide access to researcher with the assistance of a discovery tool. }\end{array}$ \\
\hline Mostly Unprocessed & $\begin{array}{l}\text { No digital access point. A significant portion of the collection is unpro- } \\
\text { cessed and minimal outline of collection contents is available only in- } \\
\text { house. A staff member may be able to provide access using a combination } \\
\text { of outline and curator's knowledge. }\end{array}$ \\
\hline Completely Unprocessed & $\begin{array}{l}\text { No digital access points or no description of collection contents. Access is } \\
\text { completely dependent on curator's knowledge. }\end{array}$ \\
\hline
\end{tabular}

The BICLM Collections Survey uncovered 335 named collections, which were ranked according to the above criteria. Of this number, 203 collections were considered processed; 36 collections were ranked as mostly processed; 13 collections were rated as unprocessed; 33 collections were considered mostly unprocessed; 24 collections were rated as mostly underprocessed; 26 collections were considered completely unprocessed. Approximately 60.6 percent of the BICLM collections were processed versus 7.8 percent of collections completely unprocessed and 31.6 percent of collections needing some sort of work to be considered processed.
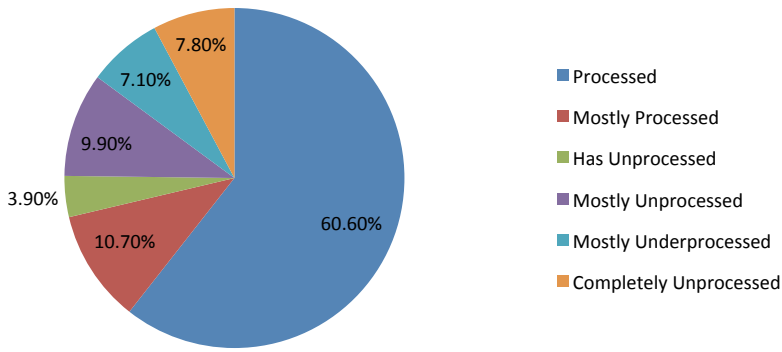

Figure 1: This pie chart illustrates BICLM collections by processing status. 
The survey immediately resulted in better intellectual control over the collections. The BICLM created a comprehensive list of all named collections, previously an impossibility. While the curator was pleasantly surprised at the relatively high percentage of collections processed, the survey indicated that of the 203 collections considered processed, 159 contained only original art, for which the process of describing and making available is less intense than it is for the unprocessed collections with a combination of formats. In addition, the extent of these unprocessed collections was very large; for example, the two largest collections, SFACA and IMCA, have significant unprocessed portions-approximately 2,400 boxes and nearly 10,000 original art items, respectively.

Ultimately, the BICLM found it helpful to prioritize processing projects, focusing first on "low-hanging fruit," or collections that needed minor work to be considered processed. Work began on improving collections discovery by creating online access points. This involved creating basic collection-level records within the OSUL catalog. For the larger unprocessed collections, this provided a quick solution to making the materials known to researchers until they could be processed. The survey also uncovered broken links in the OSUL catalog records to the art database and to the Ohio Link Finding Aid Repository. Correcting these existing catalog records were minor tasks that could be easily and quickly completed for collections to be considered processed and discoverable by researchers.

Unique to the repository, the results of the collections survey assisted BICLM in determining what exactly constitutes a collection. The BICLM depends primarily on gifts-in-kind, ranging from a single item, to many linear feet of materials. Each gift, whether original art, monographs and serials, or manuscripts, was named as a "collection" to identify and honor the donor of the materials. Some donors prefer to give a set amount of original artwork each year. Donors also give all types of cartoon-related materials, such as books, ephemera, newspaper tear sheets, and objects, along with business records and correspondence. According to procedure, incoming accessions are divided by format and placed within the appropriate workflow for art, archival processing, or MARC cataloging. Often the information on the extent of a collection is not readily available, because the contents of a single accession could be spread out and described three different ways. In the past, gifts were given the collection code ${ }^{19}$ "ONE" followed by the year and sequential number, and sometimes a single item gift was not accessioned. Because many donors gave small gifts consistently through the years (often one or multiple accessions each year), the collection code made it difficult to determine extent without consulting past paperwork. Later, the BICLM discontinued this practice and began assigning collection codes derived from the donors' initials; for example the Milton Caniff collection code is "MAC." It was difficult to determine how many items constituted a collection; when does a series of gifts from the same person become a collection named after the donor? From the survey results, the BICLM decided if a person donated more than 30 items, regardless of format or type (e.g., 30 artworks, 30 monographs or serials, or 30 objects), it should be considered a "named" collection after the donor, such as the Milton Caniff Collection. If a person donated 29 items or fewer, each object would be designated a gift of that donor. 
The survey results also affected the accessioning workflow at the BICLM. Using minimal description during the accessioning process helps manage the backlog. More detail given in an accession record could later provide an access point to the collection. As suggested by Christine Weideman in "Accessioning as Processing," collection materials can be made accessible by arranging and describing them, as well as by creating a finding aid during accessioning, resulting in the collection never entering the backlog. ${ }^{20}$ This method also reflects the central tenet of Greene and Meissner's "More Product, Less Process" that to meet the demands of both researchers and donors, archivists need to reduce the amount of time it takes to make a collection available for research. ${ }^{21}$

Previously, two assistant curators completed the accession record and recorded information in a Word document printed out and placed in the donor file before initiating the entire arrangement and description process. Responsibilities shifted to the associate curator, who became the point person, directing materials into the proper workflow by format and assigning priority. The associate curator now also enters accession information such as collection title, collection code, brief subject description, extent, and collection contents into a spreadsheet with the same information fields as on the collections survey form to consistently track the processing status of collections. The associate curator decided to start formally accessioning gift-in-kind books to better track when gifts accumulated over 30 items and became named collections. In the past, donors of gift-in-kind books were acknowledged by thank-you letters, and the publications placed in a queue to receive MARC catalog records. While steps were added to some parts of the accession process, other steps were discontinued for efficiency. During accessioning of original art, each piece was once tallied and described either by title or date. Upon review, this step duplicated work undertaken during processing the pieces into the art database. To streamline the process, pieces of art are still counted (or an amount estimated), but not described at this step. Instead, time is spent on describing archival collections during the accessioning process. Each archival collection is now rehoused into acid-free containers and a box-level inventory created, which can later be used to create a collection-level record or a simple EAD finding aid.

An unintended result, the BICLM Collections Survey became an important succession planning step, providing a smooth transition during the retirement of the founding curator, while serving as an effective method for the associate curator to develop a deeper knowledge of the collections. "Succession planning" is a term typically used in business to describe the process of preparing individuals to lead an organization and to maintain continuity during change and prevent the knowledge acquired at the company's expense by an experienced employee from "walking out the door." 22 Succession planning is also applicable to libraries as retirements are inevitable and the increase in mobility throughout employees' careers will leave gaps in management of library collections and services. ${ }^{23}$ The BICLM's strength has always resided in its unique collections of cartoon art and comic history; effective succession planning would ensure continuity of the knowledge of these collections. Documenting the founding curator's institutional memory in the survey form's notes field achieved this. The notes field included reminders to follow up with past donors on previously discussed or promised gifts; memories of 
working with donors and relationships among their heirs; particularly interesting subject materials in a collection; circumstances surrounding a collection's arrival; or the context of a collection's acquisition. The founding curator's involvement proved critical in transferring explicit and tacit knowledge to new staff. Victoria Irons Walch defines explicit knowledge as "information that is easily explained and recorded in databases and manuals, while tacit knowledge is more difficult to capture and transfer." ${ }^{24}$ Tacit knowledge "includes experience, stories, impressions and creative solutions." ${ }^{25}$ BICLM's Collections Survey is one approach to sharing tacit knowledge. Other suggested approaches to impart this type of knowledge are "shadowing, mentoring programs and communities of practice - those informal dynamic networks of knowledge sharing." ${ }^{26}$ The founding curator's involvement ensured transmission of the BICLM's culture and other intangibles that helped manage resources more effectively in the wake of the expansion.

Originally, the BICLM planned to compare survey results with those of the larger OSUL Special Collections Unprocessed Collections Survey. Unfortunately, at the time, data were unavailable because of the larger survey project's postponement due to staffing changes. Overall, the results of its Collections Survey satisfied the BICLM staff. The BICLM gained more intellectual control over materials by obtaining a clearer understanding of its backlog and the steps necessary to improve access. Secondary benefits such as documenting institutional knowledge contributed to the overall success of the project. From the survey results, the BICLM decided to move forward with creating online access points using accession information to create basic collection-level records. Meanwhile, the BICLM is currently seeking grants to address processing of the larger collections.

\section{Conclusion}

The BICLM Collections Survey was an effective planning tool to better understand the needs of collections, to allocate resources, and to assist in succession planning. Initially undertaken to meet the immediate goals of moving collections into a new facility and improving access by developing a prioritized processing plan, the collections assessment survey enabled the BICLM to centralize long-scattered information and gain intellectual control over its holdings of original cartoon art and collections related to comic history. Encouraged by the article Taking Stock and Making Hay and inspired by the success of the PACSCL Consortial Survey Initiative, the BICLM developed a survey template to consistently gather information on the state of all its holdings, processed and unprocessed, particularly their processing status and the availability of online descriptive tools, to understand how researcher access to collections could be increased.

The survey results transformed BICLM's accession process by emphasizing minimal description gathered during accessioning to repurpose the information into an access point through a finding aid or collection-level catalog record. The survey form, adapted from the PACSCL methodology, can be customized to fit a variety of needs for a small- or large-scale project and for other collections management purposes. BICLM's Collections Survey also demonstrated that an assessment survey can be completed without 
additional resources such as those provided by a grant, although a repository should plan sufficient time and staff resources.

An immediate result of the BICLM Collections Survey was the ability to list all collections within its holdings, which previously was impossible. The survey also revealed that the relatively high percentage of collections considered processed were comprised mostly of original art. While the percentage of unprocessed collections was lower, the extent of these collections was larger and consisted of contents in multiple formats. The results of the survey had the most impact on BICLM's accessioning workflows. Spending extra time during accessioning to arrange and describe the materials and create a finding aid prevents a collection from entering the backlog and quickly opens the collection to researchers, making it accessible.

The collections survey also had the unintentional secondary benefit of documenting the institutional memory of the retired founding curator and other long-time staff members. Accomplished through staffwide meetings, succession planning included reviewing the gathered information in the survey template and collectively ranking the qualitative fields of interest and quality. The recollections were recorded in an accessible format on the survey spreadsheet. The staff found this step essential, and they now have a better understanding of past collections management decisions. The collections survey served as a documentation method, capturing the difficult to impart concept of tacit knowledge and the experience, stories, and impressions of skilled employees. BICLM's experience reveals that collections surveys can be used not only as collections management and accessibility tools, but also as components of succession planning to maintain continuity during change.

\section{ABOUT THE AUTHOR}

Wendy Pflug is an associate curator and assistant professor at The Ohio State University Billy Ireland Cartoon Library and Museum. Her research focuses on issues of access to archival collections. 


\section{NOTES}

1. The term "tear sheet" refers to a page cut or removed from a publication. In this article, the term is used to refer to a single newsprint page removed from the rest of the newspaper.

2. “About Us-Holdings," Billy Ireland Cartoon Library, The Ohio State University, accessed July 15, 2014, http://cartoons.osu.edu/about-us/.

3. OSUL is currently moving to another platform to enhance the level of access that has been provided.

4. Martha O'Hara Conway and Merilee Proffitt, Taking Stock and Making Hay: Archival Collections Assessment (Dublin, OH: OCLC, 2011), 7, accessed June 9, 2014, http://www.oclc.org/content/ dam/research/publications/library/2011/2011-07.pdf.

5. Ibid.

6. Ibid., 16-18.

7. Ibid., 16 .

8. John A. Fleckner, SAA Basic Manual Series Archival Surveys, (Chicago: Society of American Archivists, 1977), 3.

9. Ibid, 15 .

10. Gregory S. Hunter, Developing and Maintaining Practical Archives: A How-to-do-it Manual (New York: Neal-Shuman Publishers, Inc., 2003), 27.

11. Conway and Proffitt, Taking Stock and Making Hay: Archival Collections Assessment, 7.

12. Or in progress at the time Taking Stock and Making Hay: Archival Collections Assessment was published in 2011.

13. "About the Project-Project Background," Philadelphia Area Consortium of Special Collections Libraries: PACSCL Consortial Survey Initiative, last modified August 23, 2007, http://www .pacsclsurvey.org/about.html.

14. Ibid.

15. Ibid.

16. "Project Documentation and Links-Survey Ratings," Philadelphia Area Consortium of Special Collections Libraries: PACSCL Consortial Survey Initiative, last modified April 16, 2008, http:// www.pacsclsurvey.org/documents/ratings.pdf.

17. The OSUL Special Collections Unit Unprocessed Collections Survey project manager resigned during the first half of 2012 and consequently the project was placed on hold.

18. Due to OSUL Special Collections Unit Unprocessed Collections Survey being placed on hold this database was never realized.

19. "Collection code" is the term used at BICLM for accession number.

20. Christine Weideman, "Accessioning as Processing," The American Archivist 62, no. 2 (2006): 277.

21. Mark A. Greene and Dennis Meissner, "More Product, Less Process: Revamping Traditional Archival Processing," The American Archivist 68, no. 2 (2005): 212.

22. Arnold Kransdorff, "Succession Planning in a Fast Changing World," Management Decision 34, no. 2 (1996): 30.

23. Kiyomi D. Deards and Gene R. Springs, Succession Planning and Implementation in Libraries: Practices and Resources (Hershey, PA: Information Science Reference, 2014), xiv.

24. Victoria Irons Walch, Elizabeth Yakel, Jeannette Allis Bastian, Nancy Zimmelman, Brenda Banks, Susan E. Davis, and Anne P. Diffendal, "Special Section on A*CENSUS (Archival Census \& Education Needs Survey in the United States)," The American Archivist 69, no. 2 (2006): 318.

25. Ibid.

26. Ibid. 